\title{
Furvina (G-1). Efectividad in vitro sobre Microorganismos Aislados de Infecciones Dérmicas en Caninos
}

\author{
Furvina (G-1) in vitro Effectiveness on Microorganisms Isolated from Skin \\ INFECTIONS IN DoGS
}

\author{
Miriam Díaz Díaz ${ }^{1,2}$, Alfredo Meneses Marcel', Ricardo Medina Marrero', Aliuska \\ Morales Helguera $^{1}$, Milagros García Bernal ${ }^{1}$, Sergio Sifontes Rodríguez ${ }^{1}$
}

\section{Resumen}

\begin{abstract}
El objetivo del presente fue evaluar la actividad in vitro de la furvina frente a microorganismos aislados de la piel de caninos con piodermitis de la ciudad de Santa Clara, Cuba. La resistencia a los agentes antibacterianos se determinó mediante el método de difusión en agar y la actividad in vitro se evaluó cuantitativamente mediante macrodilución en caldo según procedimientos internacionales. Se identificaron 50 cepas multirresistentes, siendo 47 del género Staphylococcus y 3 del género Pseudomonas. El test exacto de Fisher demostró sensibilidad altamente significativa de los microorganismos del género Staphylococcus para la ciprofloxacina. Todas las cepas fueron resistentes al menos a tres de los antibacterianos enfrentados. Las muestras evaluadas mostraron una Concentración Inhibitoria Mínima (CIM) entre $2-16 \mathrm{mg} / \mathrm{ml}$ frente a furvina, destacándose que el $83.2 \%$ de las cepas osciló entre 4 y $8 \mathrm{~g} / \mathrm{ml}$, y una Concentración Bactericida Mínima (CBM) entre 4-32 mg/ml, resaltando que el $86.2 \%$ de los aislados osciló entre 8 y $16 \mathrm{mg} /$ $\mathrm{ml}$. Todas las cepas evaluadas mostraron una $\mathrm{CIM}_{50}$ frente a furvina de $5.59 \mathrm{mg} / \mathrm{ml}(4.70$ 6.48) y una $\mathrm{CBM}_{50}$ de $11.8 \mathrm{mg} / \mathrm{ml}$ (10.0-13.6). Los resultados permiten inferir que furvina posee una actividad bactericida in vitro frente a las cepas sensibles y resistentes, aisladas de lesiones en la piel de caninos.
\end{abstract}

Palabras clave: furvina, sensibilidad, antibacterianos, microorganismos, piel, caninos

\section{Abstract}

The aim of this study was to evaluate the in vitro activity of furvina against microorganisms isolated from the skin of canines with piodermatitis in of Santa Clara, Cuba. Resistance to antibacterial agents was assessed by the diffusion method in agar and the in vitro activity was evaluated quantitatively by the broth macrodilution method

\footnotetext{
${ }^{1}$ Centro de Bioactivos Químicos, Universidad Central «Marta Abreu» de Las Villas (UCLV), Villa Clara, Cuba

${ }^{2}$ E-mail: miriamdd@uclv.cu
}

Recibido: 3 de diciembre de 2015

Aceptado para publicación: 30 de marzo de 2016 
according to international clinical laboratory standards. Fifty multiresistant strains were identified, 47 from the genus Staphylococcus and 3 from Pseudomonas. The Fisher's exact test showed highly significant sensibility of microorganisms of the genus Staphylococcus to ciprofloxacin. All strains were resistant to at least three antimicrobials. The Minimum Inhibitory Concentration (MIC) for furvina ranged from $2-16 \mathrm{mg} / \mathrm{ml}$ where $83.2 \%$ of the strains having a MIC of $4-8 \mathrm{mg} / \mathrm{mL}$. The Minimum Bactericidal Concentration (MBC) ranged from $4-32 \mathrm{mg} / \mathrm{ml}$ where $86.2 \%$ of the isolates oscillating between 8 and 16 $\mathrm{mg} / \mathrm{ml}$. All strainsshowed aMIC $\mathrm{C}_{50}$ against furvina of $5.59 \mu \mathrm{g} / \mathrm{ml}(4.70-6.48)$ and a $\mathrm{MBC}_{50}$ of $11.8 \mu \mathrm{g} / \mathrm{ml}(10.0-13.6)$. These results may infer that furvina exhibits an in vitro bactericidal activity against sensitive and resistant bacteria from canine skin lesions.

Key words: furvina, sensibility, antimicrobial, microorganisms, skin, canine

\section{INTRODUCCIÓN}

La piel posee una flora constituida por microorganismos saprófitos cuya población permanece latente $y$ en permanente mutualismo. Además, existe otra correspondiente a microorganismos transitorios que pueden llegar a la piel lesionada a partir de las mucosas superficiales o desde el medio ambiente, generándose un desequilibrio que permite la proliferación de microorganismos oportunistas y la instalación de la infección (Ihrke, 2000).

Las patologías dermatológicas son uno de los motivos de consulta más frecuentes en la práctica veterinaria de animales pequeños, posiblemente debido a los evidentes signos y lesiones que presentan los animales, los que se producen cuando se altera la función de la barrera o del sistema inmunitario cutáneo. Por otro lado, la resistencia bacteriana a los antimicrobianos es considerada un fenómeno creciente y de gran complejidad (Cain, 2013; Junjappa et al, 2013), que ha traído como consecuencia fracasos terapéuticos y persistencia del estado de enfermedad en los pacientes, siendo esto un tema de gran preocupación en Medicina Humana y Veterinaria (Kang et al., 2014; Randall et al., 2014).
Las investigaciones, tanto clínicas como epidemiológicas, han demostrado que cada vez son menos las barreras para el paso de genes de resistencia entre diferentes poblaciones bacterianas, incluida la transferencia desde bacterias comensales a patógenas, así como la transferencia de bacterias patógenas y no patógenas de los animales al hombre y al medio ambiente (Albuquerque et al., 2014; Diarra y Malouin, 2014).

En la época posterior al descubrimiento de las sulfonamidas y la penicilina raramente se probaba la sensibilidad de los microorganismos a las drogas. Los tratamientos se realizaban en forma empírica y los microorganismos generalmente eran sensibles. Solo tras el surgimiento de las cepas resistentes se tuvo que comenzar a probar la sensibilidad de los microorganismos frente a los agentes antimicrobianos (García-Sánchez et al., 2014). La búsqueda de nuevos antimicrobianos con un amplio espectro de actividad se ha incrementado en la última década por la aparición de cepas resistentes debido, en muchos casos, a su mal empleo en las terapias (Wedley et al., 2014).

En el Centro de Bioactivos Químicos (CBQ) de la Universidad Central «Marta Abreu» de Las Villas se trabaja arduamente en el desarrollo de sustancias bioactivas de- 
rivadas del furfural. Entre los de mayor grado de desarrollo se encuentra el 2-bromo-5(2-bromo-2-nitrovinil)-furano (furvina), denominado comúnmente como G-1, nueva entidad molecular, inexistente en el mercado internacional, que posee potente acción antibacteriana y antifúngica de amplio espectro, que no reconoce resistencia de bacterias y hongos a los principales antibióticos y fungicidas existentes en el mercado mundial y con un mecanismo de acción novedoso que difiere de los agentes antimicrobianos usados en la actualidad (Medina, 2007).

El presente estudio tuvo como objetivos el aislamiento de microorganismos de piel de caninos con piodermatitis y evaluar la actividad in vitro de la furvina frente a los microorganismos aislados.

\section{Materiales y Métodos}

\section{Toma de Muestras}

Las muestras provinieron de 50 caninos llevados a clínicas y consultorios veterinarios de la ciudad de Santa Clara, Cuba. Los caninos conformaban una población heterogénea de 25 machos y 25 hembras, con edades comprendidas entre 8 meses y 14 años. Estos pacientes presentaban dermatitis con lesiones sugestivas de pioderma superficiales y profundas.

Como criterio de inclusión se tuvo en cuenta que los canes no tuvieran tratamiento de antibiótico por tres semanas anteriores a la toma de las muestras. Las muestras se obtuvieron mediante hisopados de piel, antecedidas por raspado profundo, teniendo en cuenta el aspecto macroscópico de las lesiones como costras, pápulas, pústulas, escoriación, alopecia y eritema.

Las muestras fueron trasladadas y trabajadas en el Laboratorio Provincial de Diagnóstico Veterinario de Santa Clara.

\section{Cultivo y Aislamiento}

Las muestras fueron cultivadas en agar sangre a $37^{\circ} \mathrm{C}$ durante $24 \mathrm{~h}$ en aerobiosis. El género de los microorganismos se identificó a través de tinción de Gram y pruebas de catalasa y óxido-fermentación para glucosa. La tipificación de las especies se realizó por producción de hemolisinas, coagulasa, fosfatasa alcalina, reducción de nitratos, Vogues Proskauer, CAMP, TSI, rojo metilo, susceptibilidad a $5 \mu \mathrm{g}$ de novobiocina, así como por producción de ácido de D-trehalosa, sacarosa, D-ribosa, D-celobiosa, D-xylosa, $\alpha$ lactosa, D-manitol, fructosa, maltosa y Dmanosa.

\section{Antibiograma}

Las pruebas de sensibilidad a antibióticos se desarrollaron de acuerdo al método de Kirby Bauer, inoculando los aislados en caldo Müeller-Hinton e incubando inmediatamente a $37^{\circ} \mathrm{C}$, generalmente entre 2 y $6 \mathrm{~h}$ (hasta lograr una densidad equivalente al 0.5 de la escala de McFarland). Posteriormente, se sumergió un hisopo de algodón estéril en la suspensión ajustada presionando firmemente por las paredes internas del tubo por encima del nivel del líquido para eliminar el exceso de líquido del hisopo. Seguidamente se inoculó la superficie seca de una placa de agar Müeller-Hinton estriando con el hisopo toda la superficie del agar estéril, repitiendo este procedimiento dos veces más para asegurar una distribución homogénea del inóculo.

Como paso final, se estrió el hisopo por el borde del agar, seguido de $15 \mathrm{~min}$ de incubación a $37^{\circ} \mathrm{C}$ previo a la colocación de los discos con los antimicrobianos (CLSI, 2009). Las placas se incubaron de 18-24 h para su posterior lectura, determinando el halo de inhibición de las bacterias aisladas frente a los antibióticos comúnmente utilizados en la práctica clínica. Los antibióticos (discos de sensibilidad) utilizados en los ensayos de sensibilidad se encuentran agrupa- 
dos dentro de las familias de ß-lactámicos [mezlocilina $(75 \mu \mathrm{g})$, azlocilina $(75 \mu \mathrm{g})$ ], fluoroquinolonas (ciprofloxacina $(5 \mu \mathrm{g})$ ], tetraciclinas [tetraciclina $(30 \mu \mathrm{g})$ ], aminoglucósidos [gentamicina $(10 \mu \mathrm{g})$, estreptomicina $(25 \mu \mathrm{g})]$, macrólidos [eritromicina $(15 \mu \mathrm{g})$ ], cefalosporinas (cefotaxima $(75 \mu \mathrm{g})$ ] y sulfamidas [cotrimoxasoles $(25 \mu \mathrm{g})]$; además, se utilizaron discos de novobiocina $(5 \mu \mathrm{g})$.

Los microorganismos aislados se clasificaron en dependencia de los halos de inhibición para cada disco de antimicrobiano y su concentración en 'resistentes', 'intermedios' o 'sensibles', siguiendo los criterios de susceptibilidad de las normas CLSI (2009), utilizando como control de la calidad las cepas de Staphylococcus aureus ATCC 25923 y Pseudomonas aureginosa ATCC 27853.

\section{Sustancia de Ensayo y Solvente}

La sustancia de ensayo fue el producto 2-bromo-5-(2-bromo-2-nitrovinil)furano (furvina) principio activo del lote 13-3-16, sintetizado en la Planta de Producción del Centro de Bioactivos Químicos de la Universidad Central de las Villas (UCLV). Se utilizó polietilénglicol 400 de calidad farmacéutica como solvente.

\section{Actividad in vitro frente a Furvina}

Se determinó la Concentración Inhibitoria Mínima (CIM) del ingrediente farmacéutico activo furvina frente a las cepas de microorganismos por el método de macrodilución en caldo, según las CLSI(2009), empleando un rango de concentraciones de $64 \mathrm{a} 0.50 \mu \mathrm{g} / \mathrm{ml}$ y con el inóculo estandarizado $\mathrm{a} \approx 1.5 \times 10^{8}$ Unidades Formadoras de Colonias por mililitros (UFC/ml). La Concentración Bactericida Mínima (CBM) se determinó siguiendo los criterios de las CLSI (2009).

\section{Microorganismos de Ensayo}

El estudio se realizó con cepas aisladas de lesiones en piel. Estas se identificaron y caracterizaron por los métodos aceptados y establecidos en los laboratorios Provinciales de Diagnósticos Veterinarios, NRAG (Norma Ramal de la Agricultura) (NRAG 1009/ 1989 Siembra Bacteriológica; NRAG 1010/ 1989 Clasificación Microbiológica); utilizando como control de la calidad cepas de Staphylococcus aureus ATCC 25923 y Pseudomonas aureginosa ATCC 27853.

\section{Procedimientos y Técnicas}

Solución madre de la sustancia de ensayo

Se pesaron $0.0256 \mathrm{~g}$ de furvina en una balanza analítica Sartorius. Se trituró finamente el producto en un mortero estéril, disolviéndolo totalmente en polietilénglicol 400 . El contenido fue vertido en un matraz aforado de $5 \mathrm{ml}$ y se lavó con el disolvente hasta arrastrar el residuo, para enrasar finalmente con polietilénglicol 400. Se agitó hasta una completa homogenización. La concentración final de la solución madre fue de $5120 \mu \mathrm{g} / \mathrm{ml}$.

Solución de trabajo (ST) de las sustancias de ensayo

Se realizó una dilución 1/10 de la solución madre de furvina $(5120 \mu \mathrm{g} / \mathrm{ml})$ en caldo Müeller-Hinton. La concentración de la solución de trabajo de furvina fue de $512 \mu \mathrm{g} / \mathrm{ml}$.

Concentraciones de las sustancias de ensayo

Se colocaron 8 tubos en una gradilla. A partir de la ST se preparó el tubo 1 con una concentración de $64 \mu \mathrm{g} / \mathrm{ml}$ y una dilución de 1 / 8. A partir del tubo 1 se prepararon en los tubos 2,3 y 4 con diluciones de $1 / 2,1 / 4$ y $1 / 8$, respectivamente. Del tubo 4 se prepararon en los tu- 
bos 5,6 y 7 con diluciones de $1 / 2,1 / 4$ y $1 / 8$, respectivamente. Igualmente, a partir del tubo 7 se preparó el tubo 8 con una dilución de 1/2.

\section{Preparación del Inóculo}

Las cepas se sembraron inicialmente en placas con medio agar Müeller-Hinton. El método de siembra por agotamiento fue utilizado para esparcir la carga microbiana hasta lograr una completa distribución y se incubaron de 18 a $24 \mathrm{~h}$ a $37^{\circ} \mathrm{C}$. Luego se seleccionaron de 3 a 5 colonias del mismo tipo morfológico, se tocó el tope de cada colonia con un asa o aplicador estéril y fueron suspendidas en tubos que contenían $5 \mathrm{ml}$ de solución salina fisiológica. Esto resultó en una suspensión de 1 a $2 \times 10^{8} \mathrm{UFC} / \mathrm{ml}$. Después de una agitación vigorosa, el ajuste se realizó por comparación visual del tubo del inóculo con el estándar 0.5 de Mc Farland. Se transfirió $10 \mu 1$ de esta suspensión a un tubo que contenía $9.99 \mathrm{ml}$ de caldo Müeller-Hinton. La concentración final de $5 \times 10^{5} \mathrm{UFC} / \mathrm{ml}$. Se hizo una agitación intensa para obtener una total homogenización.

\section{Determinación de la Concentración Inhibitoria Mínima (CIM)}

La CIM se determinó por el método de macrodilución en caldo. Se realizaron tres réplicas por cepa con sus respectivos controles. Inicialmente se adicionó $0.5 \mathrm{ml}$ de cada concentración a todos los tubos de trabajo, excepto a los controles (positivo y negativo). Posteriormente, se adicionó $10 \mu \mathrm{l}$ del inóculo ajustado $\left(5 \times 10^{5} \mathrm{UFC} / \mathrm{ml}\right)$ a todos los tubos, exceptuando al tubo control negativo, al cual se le añadió $1 \mathrm{ml}$ de caldo de Müeller-Hinton.

Como en los tubos correspondientes a las diluciones de trabajo de furvina ( 64 a 0.50 $\mu \mathrm{g} / \mathrm{ml})$ se añadieron iguales volúmenes del inóculo. Las diluciones finales de los mismos se correspondieron con una dilución 1:2 de estas; es decir, de 32 a $0.25 \mu \mathrm{g} / \mathrm{ml}$.

Se realizó control de pureza y viabilidad del inóculo, subcultivando una alícuota de cada suspensión sobre una placa de agar Müeller-Hinton. La incubación se realizó de 18 a 24 h a $37^{\circ} \mathrm{C}$.

La CIM se definió como la menor concentración de la sustancia de ensayo que inhibió el crecimiento visible del microorganismo en las condiciones de incubación (tiempo, temperatura, oxigenación) acordes a las exigencias culturales del mismo.

\section{Determinación de la Concentración Bactericida Mínima (CBM)}

Se tomó $100 \mu 1$ con una pipeta regulable de los tubos de las concentraciones de ensayo donde no se observó crecimiento visible y se añadieron a tres placas con agar MüellerHinton, distribuyendo con espátulas de Drigalsky. Después de un reposo de 15 a 30 min, las placas fueron incubadas de 18-24 h a $37^{\circ} \mathrm{C}$. Luego se procedió al conteo de UFC utilizando un contador de colonias.

La CBM se definió como la menor concentración de la sustancia de ensayo que mató el 99.9\% del inóculo inicial de las bacterias, según las condiciones de incubación (tiempo, temperatura, oxigenación) acordes a las exigencias culturales del mismo, indicativo de un efecto bactericida.

\section{Análisis Estadístico}

Se calcularon los porcentajes de respuesta de los gérmenes aislados (Staphylococus sp y Pseudomonas aeruginosa) a los antibióticos enfrentados y se contrastó la existencia de sensibilidad con las variables tipo de microorganismo y antibiótico empleado. Para ello se empleó el programa SPSS v. 21.0. Se utilizó el test exacto de Fisher, considerando significativos los valores de $\mathrm{p}$ inferiores a 0.05 .

Para estimar las CIM y CBM para el 50 y $90 \%$ de las cepas evaluadas, se realizó ajuste no lineal de las curvas concentración versus el porcentaje de cepas inhibidas al modelo de Emax sigmoidea (Holford y 
Cuadro 1. Microorganismos aislados de la piel en caninos de la ciudad de Santa Clara, Cuba

\begin{tabular}{lll}
\hline Aislamientos & $\mathrm{n}^{1}$ & Código \\
\hline S. aureus & 36 & $\mathrm{LV}^{2}(2,4,5,6,7,8,9,10,11,14,15,20$, \\
& & $21,22,23,25,27,28,29,30,31,32,33,34$, \\
& & $38,39,40,41,42,43,44,46,47,48,49,50)$ \\
S. intermedius & 7 & $\mathrm{LV}(13,16,18,24,26,36,37)$ \\
S. coagulasa negativo & 3 & $\mathrm{LV}(3,35,45)$ \\
Pseudomonas aeruginosa & 3 & $\mathrm{LV}(1,17,19)$ \\
S. saprophyticus & 1 & $\mathrm{LV}(12)$ \\
\hline
\end{tabular}

${ }^{1}$ Cantidad de microorganismos aislados

${ }^{2}$ Laboratorio Veterinario (número de ai slamiento)

Sheiner, 1981) empleando el paquete estadístico Statistica v. 8.0 (StatSoft Inc; www.statsoft.com).

\section{Resultados y Discusión}

\section{Aislamiento e identificación}

En las muestras de hisopado de piel de la población de canes en estudio $(\mathrm{n}=50)$, se aislaron 47 bacterias del género Staphylococcus y tres de Pseudomonas (Cuadro 1).

Los resultados muestran que Staphylococcus coagulasa positivo (ECP) fue el microorganismo bacteriano más frecuente, coincidiendo con otros autores (Bemis et al., 2014). El 86\% de los aislamientos correspondieron a microorganismos del género Staphylococcus ( $S$. aureus, $72 \%$ y $S$. intermedius, 14\%) (Cuadro 2). Los dos microorganismos predominantes en este estudio han sido señalados por otros autores como agentes etiológicos predominantes en las infecciones de la piel en caninos (Krogh y Kristensen, 1981; Ghidini et al., 2011). Sin embargo, Cox (2008) describe que $S$.
Cuadro 2. Distribución porcentual de microorganismos aislados de caninos con piodermitis $(n=50)$ en la ciudad de Santa Clara, Cuba

\begin{tabular}{lc}
\hline Microorganismos & $\begin{array}{c}\text { Porcentaje } \\
(\%)\end{array}$ \\
\hline $\begin{array}{l}\text { Staphylococcus aureus } \\
\begin{array}{l}\text { Staphylococcus } \\
\text { intermedius }\end{array}\end{array}$ & 72 \\
$\begin{array}{l}\text { Staphylococcus coagulasa } \\
\text { negativo }\end{array}$ & 6 \\
$\begin{array}{l}\text { Staphylococcus } \\
\text { saprophyticus } \\
\text { Pseudomonas aeruginosa }\end{array}$ & 6 \\
\hline
\end{tabular}

intermedius es el más prevalente en infecciones de piel, seguido de $S$. aureus. Asimismo, es importante destacar que la mayoría de autores señalan como principal agente productor de piodermas canina a $S$. intermedius (Fitzgerald, 2009; Penna et al., 2014), aunque estudios moleculares recientes han hecho posible una nueva reclasificación y señalan S. pseudointermedius como la princi- 
Cuadro 3. Sensibilidad al antibiograma de cepas aisladas de hisopados de piel en infecciones dérmicas en caninos

\begin{tabular}{llccc}
\hline \multicolumn{2}{l}{ Antimicrobianos } & Sensible & Intermedio & Resistente \\
\hline Co-trimoxazoles & $(25 \mu \mathrm{g})$ & 17 & 7 & 26 \\
Tetraciclina & $(30 \mu \mathrm{g})$ & 19 & 11 & 20 \\
Estreptomicina & $(25 \mu \mathrm{g})$ & 27 & 8 & 15 \\
Azlocilina & $(75 \mu \mathrm{g})$ & 3 & 0 & 0 \\
Ciprofloxacina & $(5 \mu \mathrm{g})$ & 34 & 8 & 8 \\
Gentamicina & $(10 \mu \mathrm{g})$ & 25 & 10 & 15 \\
Eritromicina & $(15 \mu \mathrm{g})$ & 15 & 12 & 23 \\
Mezlocilina & $(75 \mu \mathrm{g})$ & 3 & 0 & 0 \\
Cefotaxime & $(75 \mu \mathrm{g})$ & 1 & 0 & 49 \\
\hline
\end{tabular}

pal causa de piodermas canina (Iyori et al., 2011; Paul et al., 2014).

Se requieren mayores investigaciones sobre la participación de $S$. aureus, $S$. intermedius y $S$. pseudointermedius en lesiones dérmicas caninas, utilizando técnicas moleculares que permitan ampliar el estudio epidemiológico hacia la diferenciación del agente causal como punto de partida en la correcta elección de los antibióticos para los ensayos de sensibilidad.

\section{Sensibilidad Antimicrobiana}

Todas las cepas aisladas fueron sometidas al antibiograma y los resultados se muestran en el Cuadro 3.

Estudios hechos sobre susceptibilidad antibiótica han mostrado grandes variaciones en su respuesta dependiendo de la región geográfica. En el presente estudio se encontró sensibilidad altamente significativa del género Staphylococcus frente a ciprofloxacina (72.3\%; Cuadro 4). Aunque esta quinolona de segunda generación, de uso oral, es un antibiótico de amplio espectro, solamente 34 de las 47 cepas de Staphylococcus sp aisladas fueron sensibles a este antibiótico; mientras que las tres cepas de Pseudomonas aeruginosa manifestaron resistencia al mismo. Este resultado difiere con el estudio de Escribano et al. (2009), donde el 75\% de las cepas de Pseudomonas sp aisladas de muestras cutáneas caninas mostraron sensibilidad.

El antibiótico con mayor resistencia a bacterias del género Staphylococcus fue la cefotaxima $(97.9 \%)$, cefalosporina parenteral de tercera generación de amplio espectro, sobre todo contra gérmenes Gram negativos. Un comportamiento similar ocurrió con $P$. aeruginosa donde todas las muestras presentaron resistencia. Resultados diferentes fueron enconrados por Antúnez et al. (2009), donde las cefalosporinas exhibieron los mayores índices de sensibilidad (88-97\%). Estos agentes son conocidos además por producir resistencia en muy raras ocasiones (Kwochka, 2000), aunque Harbarth y Samore (2005) han reportado cepas resistentes a 
Cuadro 4. Sensibilidad al antibiograma de los dos géneros de microorganismos aislados de hisopados de piel en infecciones dérmicas en caninos

\begin{tabular}{|c|c|c|c|c|c|}
\hline \multirow{2}{*}{ Antibióticos } & & \multicolumn{2}{|c|}{$\begin{array}{l}\text { Staphylococcus } \mathrm{sp} \\
(\mathrm{n}=47)\end{array}$} & \multicolumn{2}{|c|}{$\begin{array}{l}\text { Pseudomonas aeruginosa } \\
\qquad(\mathrm{n}=3)\end{array}$} \\
\hline & & Sensibles & $\begin{array}{c}\text { No sensibles } \\
(\mathrm{I}, \mathrm{R})^{1}\end{array}$ & Sensibles & $\begin{array}{c}\text { No sensibles } \\
(I, R)\end{array}$ \\
\hline Co-trimoxazol & $(25 \mu \mathrm{g})$ & $36.2 \%$ & $63.8 \% * *$ & - & $6 \%$ \\
\hline Tetraciclina & $(30 \mu \mathrm{g})$ & $40.4 \%$ & $59.6 \%$ & - & $6 \%$ \\
\hline Estreptomicina & $(25 \mu \mathrm{g})$ & $57.5 \%$ & $42.6 \%$ & - & $6 \%$ \\
\hline Azlocilina & $(75 \mu \mathrm{g})$ & - & - & $6 \%$ & - \\
\hline Ciprofloxacina & $(5 \mu \mathrm{g})$ & $72.3 \% * * *$ & $27.7 \%$ & - & $6 \%$ \\
\hline Gentamicina & $(10 \mu \mathrm{g})$ & $53.2 \%$ & $46.8 \%$ & $2 \%$ & $4 \%$ \\
\hline Eritromicina & $(15 \mu \mathrm{g})$ & $31.9 \%$ & $68.1 \% * *$ & - & $6 \%$ \\
\hline Mezlocilina & $(75 \mu \mathrm{g})$ & - & - & $6 \%$ & - \\
\hline Cefotaxima & $(75 \mu \mathrm{g})$ & $2.1 \%$ & $97.9 \% * * *$ & - & $6 \%$ \\
\hline
\end{tabular}

Test Exacto de Fisher $* * p<0.01, * * * p<0.001$

${ }^{1}$ I, R (Intermedio y Resistente)

cefalosporinas de tercera generación portadoras de betalactamasas de amplio espectro (BLEA).

Otros antibióticos que mostraron resistencia a bacterias del género Staphylococcus fueron la eritromicina $(68.1 \%)$ y $\operatorname{los}$ cotrimoxazoles (63.8\%) (Cuadro 4); resultados semejantes a los obtenidos por Antúnez et al. (2009), quienes mostraron 54\% de resistencia con los cotrimoxazoles (sulfametoxazol-trimetropim). Por otro lado, Ganiere et al. (2005), trabajando con 50 cepas aisladas de piodermas caninas encontraron $42 \%$ de resistencia a tres o más antimicrobianos, clasificándolas como multirresistentes; mientras que en el presente estudio el 10,36 y $54 \%$ de los aislados fueron resistentes a 3, 4 y 5 o más antibióticos, respectivamente. Asimismo, todas las muestras fueron simultáneamente resistentes a tres o más antimicrobianos, por lo que serían clasificadas como multirresistentes.
La resistencia mostrada frente a estos antimicrobianos pudiera ser consecuencia del uso continuo e indiscriminado sin previa investigación de antibiorresistencia y al tratamiento empírico como práctica habitual en la población en estudio.

\section{Susceptibilidad in vitro a Furvina}

La actividad in vitro de furvina fue evaluada mediante el método de macrodilución en caldo frente a 47 cepas de 4 especies de bacterias Gram positivas y 3 cepas de una especie de bacterias Gram negativas. En estudios previos con furvina se determinó que la CIM in vitro frente a una cepa de $S$. aureus fue de $8 \mu \mathrm{g} / \mathrm{ml}$ (García et al., 2000); resultados similares a la presente investigación, donde los valores para Staphylococcus sp se encontraban entre 2 y $16 \mu \mathrm{g} / \mathrm{ml}$ (Cuadro 5). Asimismo, cabe destacar que osciló entre 4 y $8 \mathrm{mg} / \mathrm{ml}$ en el $83.2 \%$ de las cepas. 
Cuadro 5. Concentración Inhibitoria Mínima (CIM) y Concentración Bactericida Mínima (CBM) de Furvina frente a cepas aisladas de hisopados de piel en infecciones dérmicas en caninos

\begin{tabular}{lcc}
\hline Microorganismo & $\begin{array}{c}\mathrm{CIM} \\
(\mu \mathrm{g} / \mathrm{ml})\end{array}$ & $\begin{array}{c}\mathrm{CBM} \\
(\mu \mathrm{g} / \mathrm{ml})\end{array}$ \\
\hline Staphylococcus aureus & $2-16$ & $4-32$ \\
Staphylococcus intermedius & $4-8$ & $8-16$ \\
Staphylococcus saprophyticus & 2 & 4 \\
Staphylococcus coagulasa negativo & $4-8$ & $4-8$ \\
Pseudomonas aeruginosa & 8 & $16-32$ \\
\hline
\end{tabular}

Cuadro 6. Concentración Inhibitoria Mínima (CIM50 y CIM90) y Concentración Bactericida Mínima (CBM50 y CBM90) de furvina frente a las cepas resistentes ${ }^{1}$ provenientes de infecciones dérmicas en caninos

\begin{tabular}{lccccc}
\hline Microorganismos & $\mathrm{n}$ & $\begin{array}{c}\mathrm{CIM50} \\
\mu \mathrm{g} / \mathrm{mL}\end{array}$ & $\begin{array}{c}\mathrm{CIM90} \\
\mu \mathrm{g} / \mathrm{mL}\end{array}$ & $\begin{array}{c}\mathrm{CBM} 50 \\
\mu \mathrm{g} / \mathrm{mL}\end{array}$ & $\begin{array}{c}\mathrm{CBM90} \\
\mu \mathrm{g} / \mathrm{mL}\end{array}$ \\
\hline $\begin{array}{l}\text { Staphylococcus } \\
\text { aureus }\end{array}$ & 36 & $\begin{array}{c}5.5 \\
(4.7-6.3)\end{array}$ & $\begin{array}{c}15.4 \\
(13.1-17.6)\end{array}$ & $\begin{array}{c}12.1 \\
(9.9-14.3)\end{array}$ & $\begin{array}{c}32.6 \\
(26.6-38.6)\end{array}$ \\
$\begin{array}{l}\text { Staphylococcus } \\
\text { intermedius }\end{array}$ & 7 & $\begin{array}{c}6.0 \\
(4.5-7.5)\end{array}$ & $\begin{array}{c}13.5 \\
(10.2-16.9)\end{array}$ & $\begin{array}{c}8.09 \\
(7.1-9.1)\end{array}$ & $\begin{array}{c}25.8 \\
(22.7-28.8)\end{array}$ \\
\hline $\begin{array}{l}\text { Evaluación } \\
\text { general }\end{array}$ & 50 & $\begin{array}{c}5.6 \\
(4.7-6.5)\end{array}$ & $\begin{array}{c}15.0 \\
(12.6-17.4)\end{array}$ & $\begin{array}{c}11.08 \\
(10.0-13.6)\end{array}$ & $\begin{array}{c}32.6 \\
(27.6-37.5)\end{array}$ \\
\hline
\end{tabular}

${ }^{1}$ No fue posible la evaluación de Staphylococcus coagulasa negativo, Staphylococcus saprophyticus y Pseudomonas aeruginosa por el número reducido de cepas

La CIM para $P$. aeruginosa fue de 8 $\mu \mathrm{g} / \mathrm{ml}$, coincidiendo con otros resultados (Medina et al., 2000; Morales et al., 2014). En estudios previos se estableció una CIM mayor de $32 \mu \mathrm{g} / \mathrm{ml}$ como criterio de resistencia a furvina, debido a que más del $90 \%$ de la CIM fueron menores o iguales a dicho valor para las cepas bacterianas evaluadas (Medina et al., 2000).
La CBM de furvina varió entre 4 y 32 $\mu \mathrm{g} / \mathrm{ml}$ frente a Staphylococcus sp con predominio del $86.2 \%$ entre 8 y $16 \mu \mathrm{g} / \mathrm{ml}$; coincidiendo con García et al. (2000), quienes reportaron valores de CBM para furvina de 32 $\mu \mathrm{g} / \mathrm{ml}$. La CBM frente a $P$. aeruginosa varió entre 16 y $32 \mu \mathrm{g} / \mathrm{ml}$, con un comportamiento similar a los resultados obtenidos por Morales et al. (2014) (Cuadro 5). 
Los resultados de la evaluación general del CIM50-90 y CBM50-90 de furvina al enfrentar las 43 cepas multiresitentes en estudio indican que la sustancia de ensayo posee una actividad bactericida (Cuadro 6); resultados que coinciden con lo reportado por Blondeau et al. (1999), quienes señalan valores de CIM para furvina de 4 a $32 \mu \mathrm{g} / \mathrm{ml}$, al enfrentarlo contra 198 cepas de bacterias $S$. aureus multiresitentes.

\section{Conclusiones}

- Se aislaron 47 cepas del género Staphylococcus y 3 del género Pseudomonas.

- Todas las cepas aisladas de hisopados de piel en infecciones dérmicas en caninos de la ciudad de Santa Clara, Cuba, mostraron resistencia en al menos 3 de los 10 antibióticos enfrentados.

- El principio activo furvina posee una actividad bactericida in vitro frente a cepas multirresistentes.

\section{Literatura Citada}

1. Albuquerque $S A$, Magnavita AP, Ferrao SP, Gualberto SA, Faleiro AS, Figueiredo AJ, Matarazzo SV. 2014. Daily ingestion of tetracycline residue present in pasteurized milk: a public health problem. Environ Sci Pollut Res Int 21:3427-3434. doi: 10.1007/s11356013-2286-5

2. Antúnez A, Calle E, Morales C, Falcón P, Pinto J. 2009. Frequency of pathogens isolated in clinical cases of canine pioderma and its antimicrobial susceptibility. Rev Inv Vet Perú 20: 332338. doi: 10.15381/rivep.v20i2.635

3. Bemis DA, Bryant MJ, Reed PP, Brahmbhatt RA, Kania SA. 2014. Synergistic hemolysis between betalysin-producing Staphylococcus species and Rothia nasimurium in primary cultures of clinical specimens obtained from dogs. J Vet Diagn Inv 26: 437-441. doi: $10.1177 / 1040638714532098$

4. Blondeau J, Casteñedo N, González O, Medina R, Silveira E. 1999. In vitro evaluation of G-1. A novel antimicrobial compound. Int J Antimicrob Agents 11: 163-166.

5. Cain CL. 2013. Antimicrobial resistance in staphylococci in small animals. Vet Clin North Am Small Anim Pract 43: 19-40. doi: 10.1016/j.cvsm.2012.09.003

6. [CLSI] Clinical and Laboratory Standards Institute. 2009. Performance standards for antimicrobial susceptibility testing. Twentieth informational supplement. M100-S20. Wayne, PA, USA.

7. Cox H. 2008. Infecciones por estafilococos. En: Greene CE (ed). Enfermedades infecciosas del perro y el gato. Buenos Aires: Ed Intermédica. $p$ 352-356.

8. Diarra MS, Malouin F. 2014. Antibiotics in Canadian poultry productions and anticipated alternatives. Front Microbiol 5: 282. doi: 10.3389/ fmicb.2014.00282

9. Escribano C, Ordeix L, Pol G, Puigdemont A, Brazis P. 2009. Sensibilidad de Pseudomonas spp frente a las quinolonas en infecciones óticas y cutáneas en el perro y el gato. Clin Vet Peq Anim 29: 203-207.

10. Fitzgerald JR. 2009. The Staphylococcus intermedius group of bacterial pathogens: species re-classification, pathogenesis and the emergence of meticillin resistance. Vet Dermatol 20: 490-495. doi: 10.1111/j.1365-3164.2009. 00828.x

11. Ganiere JP, Medaille C, Mangion $C$. 2005. Antimicrobial drug susceptibility of Staphylococcus intermedius clinical isolates from canine pyoderma. J Vet Med B Infect Dis Vet Public Health 52: 25-31.

12. García M, Medina R, Toraño P, Gutiérrez F. 2000. Comparación del efecto postantibiótico del G-1 y la gentamicina frente a cepas de Staphylo- 
coccus aureus y Escherichia coli. Acta Farm Bonaerense 19: 225-230.

13. García-Sánchez JE, García-Sánchez E, García-García MI. 2014. Estudios de sensibilidad en bacterias anaerobias. Enferm Infecc Microbiol Clin 32(Supl 1): 23-29.

14. Ghidini F, Piancastelli C, Taddei S, Gandolfo E, Cavirani S, Cabassi CS. 2011. Antibiotic sensitivity of bacterial isolates from cases of canine dermatitis. New Microbiol 34: 403-408.

15. Harbarth S, Samore M. 2005. Antimicrobial resistance determinants and future control. Emerg Infec Dis 11: 794-801. doi: 10.3201/eid1106.050167

16. Holford NH, Sheiner LB. 1981. Understanding the dose-effect relationship: clinical application of pharmacokinetic-pharmacodynamic models. Clin Pharmacokinet 6: 429-453. doi: 10.1208/ s12248-011-9306-5

17. Ihrke PJ. 2000. Infecciones integumentarias - infecciones bacterianas de la piel. En: Greene G (ed). Enfermedades infecciosas en perros y gatos. México DF: McGraw-Hill Interamericana. p 595602.

18. Iyori K, Futagawa-Saito K, Hisatsune J, Yamamoto M, Sekiguchi M, Ide K, Son WG, et al. 2011. Staphylococcus pseudintermedius exfoliative toxin EXI selectively digests canine desmoglein 1 and causes subcorneal clefts in canine epidermis. Vet Dermatol 22:319-326. doi: 10.1111/j.1365-3164.2011.00952.x

19. Junjappa RP, Desai SN, Roy P, Narasimhaswamy $N, \quad R a j \quad J R$, Durgaiah M, Vipra A, et al. 2013. Efficacy of anti-staphylococcal protein P128 for the treatment of canine pyoderma: potential applications. Vet Res Commun 37: 217-228. doi: 10.1007/ s11259-013-9565-y

20. Kang MH, Chae MJ, Yoon JW, Kim SG, Lee SY, Yoo JH, Park HM. 2014. Antibiotic resistance and molecular characterization of ophthalmic Staphylo- coccus pseudintermedius isolates from dogs. J Vet Sci 15: 409-415. doi: 10.4142/ jvs.2014.15.3.409

21. Krogh HV, Kristensen S. 1981. A study of skin diseases in dogs and cats. VI. Microflora of the major canine pyodermas. Nord Vet Med 33: 17-22.

22. Kwochka K. 2000. Management of recurrent pyoderma. En: XVII Congreso Panamericano de Ciencias Veterinarias. Panamá.

23. Medina R. 2007. Actividad antimicrobiana in vitro e in vivo del 2-bromo-5(2-bromo-2-nitrovinil)-furano frente a bacterias y hongos. Tesis Doctoral. La Habana: Instituto Finlay. 144 p.

24. Medina R, García M, Fabré JE, Rodríguez J. 2000. Inducción de resistencia in vitro al 1-(5-bromofur-2-il)-2bromo-2-nitroetano (G-1) frente a cepas de Candida albicans y Pseudomonas aeruginosa. Acta Farm Bonaerense 19: 289-294.

25. Morales Y, Medina R, Garcia M, Casanova M, Rodríguez, R, Fernández $N$, Guerra M, et al. 2014. Actividad in vitro de furvina frente a bacterias Gram negativas multirresistentes. CENIC Cienc Biol 45(1): 45-50.

26. NRAG. Norma Ramal de la Agricultura. 1009/1989 «Siembra Bacteriológica».

27. NRAG. Norma Ramal de la Agricultura. 1010/1989 «Clasificación Microbiológica».

28. Paul NC, Damborg P, Guardabassi L. 2014. Dam-to-offspring transmission and persistence of Staphylococcus pseudintermedius clones within dog families. Vet Dermatol 25: 3-e2. doi: 10.1111/vde. 12090

29. Penna B, Rabello RF, Lilenbaum W. 2014. Comparison of cefoxitin disk diffusion test and mecA gene PCR results for methicillin resistance detection in Staphylococcus intermedius group isolates from canine origin in Brazil. Braz J Microbol 45: 235-237. doi: 10.1590/ S1517-83822014000100033 
30. Randall L, Heinrich K, Horton R, Brunton L, Sharman M, Bailey-Horne V, Sharma M, et al. 2014. Detection of antibiotic residues and association of cefquinome residues with the occurrence of Extended-Spectrum beta-Lactamase (ESBL)-producing bacteria in waste milk samples from dairy farms in England and Wales in 2011. Res Vet Sci 96: 15-24. doi: 10.1016/j.rvsc.2013.10.009
31. Wedley AL, Dawson S, Maddox TW, Coyne KP, Pinchbeck GL, Clegg P, Jamrozy D, et al. 2014. Carriage of Staphylococcus species in the veterinary visiting dog population in mainland UK: molecular characterisation of resistance and virulence. Vet Microbiol 170: 81-88. doi: 10.1016/j.vetmic. 2014.01.015 